\title{
Adipose Tissue-Derived Stromal Cells as a Novel Option for Regenerative Cell Therapy
}

\author{
Hironori Nakagami ${ }^{1}$, Ryuichi Morishita ${ }^{3}$, Kazuhisa Maeda ${ }^{2}$, Yasushi Kikuchi ${ }^{1}$, Toshio Ogihara ${ }^{4}$, \\ and Yasufumi Kaneda ${ }^{1}$
}

${ }^{1}$ Division of Gene Therapy Science, Graduate School of Medicine, Osaka University, Osaka, Japan.

${ }^{2}$ Medical Center for Translational Research, Osaka University Hospital, Osaka, Japan.

${ }^{3}$ Division of Clinical Gene Therapy, Graduate School of Medicine, Osaka University, Osaka, Japan.

${ }^{4}$ Department of Geriatric Medicine, Graduate School of Medicine, Osaka University, Osaka, Japan.

\begin{abstract}
Adult stem cells hold great promise for use in tissue repair and regeneration, and the delivery of autologous progenitor cells into ischemic tissue is emerging as a novel therapeutic option. We and others have recently demonstrated the potential impact of adipose tissue-derived stromal cells (ADSC) on regenerative cell therapy for ischemic diseases. The main benefit of ADSC is that they can be easily harvested from patients by a simple, minimally invasive method and also easily cultured. Cultured ADSC can be induced to differentiate into not only adipocytes, but also bone, neurons or endothelial cells in certain conditions. Interestingly, they secrete a number of angiogenesis-related cytokines, such as vascular endothelial growth factor (VEGF) and hepatocyte growth factor (HGF), which might be suitable for regenerative cell therapy for ischemic diseases. In the ischemic mouse hindlimb, the angiogenic score was improved in the ADSC-treated group. Moreover, recent reports demonstrated that these ADSC can also be induced to differentiate into cardiac myocytes. These adipose tissuederived cells have potential in angiogenic cell therapy for ischemic disease, and might be applied for regenerative cell therapy instead of bone marrow cells in the near future.
\end{abstract}

J Atheroscler Thromb, 2006; 13:77-81.

Key words; Adipose tissue, Regenerative cell therapy, Angiogenesis, Growth factor

\section{Introduction}

Adult stem cells hold great promise for use in tissue repair and regeneration, and there has been continuing interest in both the biology and potential therapeutic applications of adult stem cells from bone marrow ${ }^{1,2)}$, referred to as either mesenchymal stem cells or marrow stromal cells (MSC). MSC are the most extensively characterized, and can differentiate into multiple cell phenotypes, including bone, fat, cartilage, muscle, epithelium, and neural progenitors ${ }^{3-5}$. In recent years, interest has rapidly grown in the developmental plasticity and therapeutic potential of

Address for correspondence: Hironori Nakagami, Department of Gene Therapy Science, Osaka University Graduate School of Medicine, 2-2 Yamada-oka, Suita 565-0871, Japan.

E-mail: nakagami@gts.med.osaka-u.ac.jp

Received: November 24, 2005

Accepted for publication: December 8, 2005 stromal cells isolated from adipose tissue ${ }^{5,6)}$. Adipose tissue represents an abundant, practical, and appealing source of donor tissue for autologous cell replacement.

\section{Characteristics of Adipose Tissue-Derived Stromal Cells (ADSC)}

Several groups have demonstrated that mesenchymal cells within the stromal-vascular fraction of subcutaneous adipose tissue display multilineage developmental plasticity ${ }^{6,7)}$. These cells have alternatively been referred to as processed lipoaspirate cells (PLA), adipose-derived stem cells, adipose-derived stromal cells, and adipose-derived mesenchymal progenitor cells. It is also likely that cells previously considered preadipocytes are essentially the same population. These names reflect a lack of consensus and an evolving knowledge base with regard to the anatomic origin, phenotype, and function of these cells. We have 

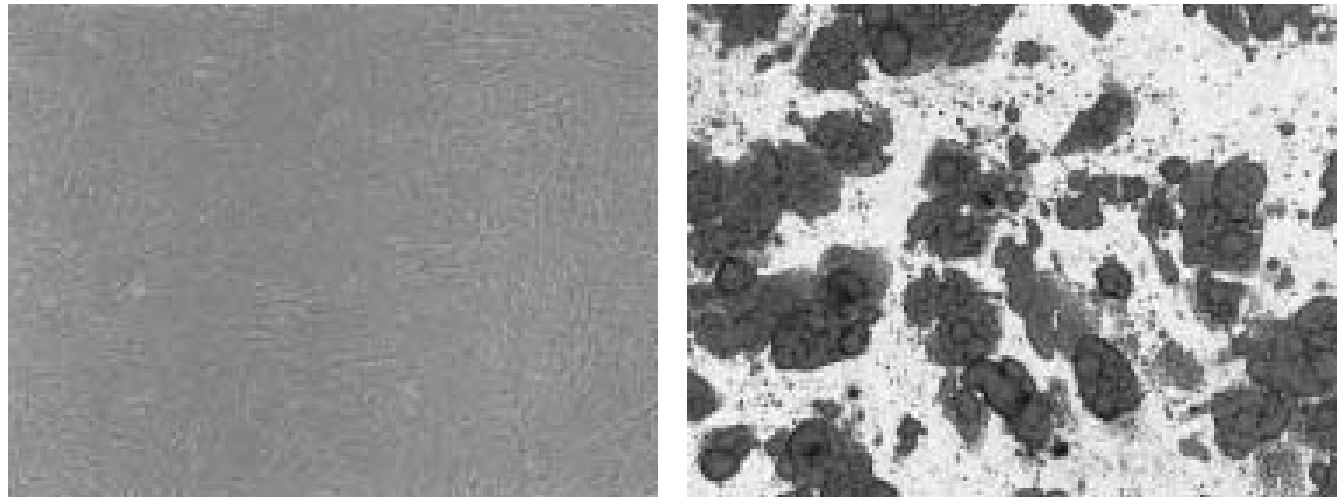

Fig. 1. Typical images of cultured ADSC (left panel) and oil red staining of cultured ADSC in phase contrast microscopy. Before oil staining. ADSC were stimulated with 10\% FBS DMEM containing $0.5 \mathrm{mM}$ IBMX, $1 \mu \mathrm{M}$ dexamethasone, $10 \mu \mathrm{M}$ insulin, and $200 \mu \mathrm{M}$ indomethacin.

called these cells adipose tissue-derived stromal cells (ADSC), which clearly reflects their origin and char$\operatorname{acter}^{8)}$.

There are obvious similarities between ADSC and MSC. Both represent the stromal cell fraction isolated from an adipose depot (subcutaneous tissue for the former, bone marrow for the latter) on the basis of adherence to tissue culture plastic. While an extensive body of work exists pertaining to the phenotypic characterization of MSC, the phenotypic characterization of ADSC is in its infancy. In our analysis of stem cellrelated surface markers, Sca1(ly-6A/E) and CD44 antigen were expressed, but not c-kit, Lin, CD11b, CD31, CD34, or CD45 in ADSC obtained from $\mathrm{C} 57 \mathrm{Bl} / 6 \mathrm{mice}^{8}$. In a recent report, MSC obtained from $\mathrm{C} 57 \mathrm{Bl} / 6$ mice showed high levels of Scal and CD34, but not c-kit, Lin, CD11b, CD31, or CD45 ${ }^{9}$. This suggests that ADSC include a similar population of mesenchymal stem cells, but no hematopoietic stem cells from bone marrow. Of importance, these characteristics of ADSC surface markers were conserved after several passages of cell expansion. As shown in Fig. 1, these cells look like fibroblasts and can differentiate into not only adipocytes, but also chondrogenic and osteogenic lineages in vitro, as described previously.

As adipose tissue is known to secrete a number of cytokines, we focused on the secretion of angiogenesis-related cytokines from ADSC. In an analysis using the quantitative real time PCR method, we observed relatively high levels of HGF (hepatocyte growth factor), VEGF (vascular endothelial growth factor), PGF (placental growth factor) and TGF (transforming growth factor)- $\beta$, moderate expression of FGF (fibroblast growth factor)-2 and Ang (angiopoietin)-1, and a low level of Ang-2 in ADSC, and it was also demon- strated that ADSC secreted multiple angiogenic growth factors, such as VEGF and HGF, at levels that are bioactive ${ }^{10,11)}$. Katz et al. recently used microarrays to evaluate genes relating to angiogenesis and the extracellular matrix in undifferentiated human ADSC isolated from three separate donors ${ }^{7}$. The most highly transcribed genes related to functional groupings such as cell adhesion, matrix proteins, growth factors and receptors, and proteases, and the transcription in ADSC had many similarities to the profile of bone marrow mesenchymal stem cells. Of importance, a recent study suggests that the very exposure of ADSC to plastic and their duration in culture (i.e., time on plastic) and the culture medium used significantly change the cell surface phenotypic profile of each cell. Another group demonstrated that human ADSC contain distinct cell populations expressing three stem cell markers, CD34, CD133 - commonly used as a hematopoietic stem cell or endothelial progenitor cell marker, and ABCG2 - recently described as identifying primitive stem cells, and FACS analysis showed that more than $90 \%$ of ADSC were positive for CD34 ${ }^{12)}$. These results suggest that freshly isolated ADSC contain significant numbers of cells positive for markers of hematopoietic lineages and endothelial cells (e.g., CD45, CD14, CD144, CD34), which notably decreased after 3-5 days in culture. This emerging picture is a primary reason why we incorporate adherence into the description of these cells, so as to distinguish them from freshly isolated cells from adipose tissue that have not been exposed to plastic and which have a significantly different cell surface phenotypic profile. 

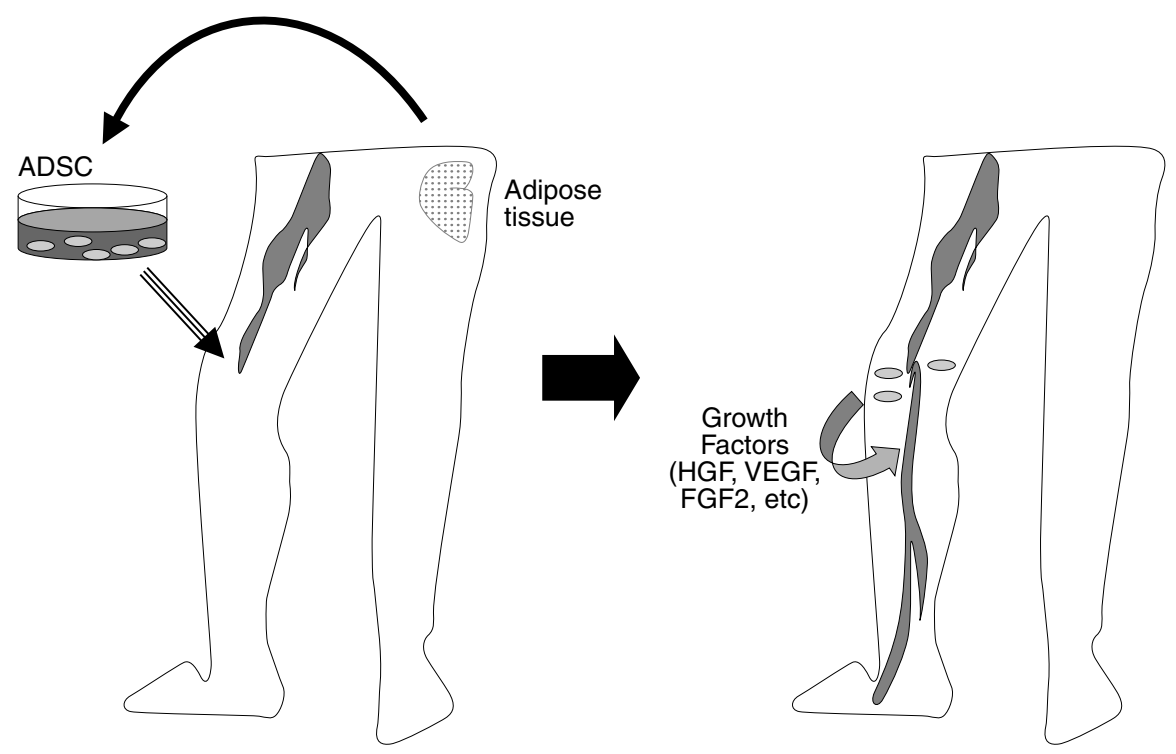

Fig. 2. Schema of ADSC-based angiogenic therapy. ADSC to be injected are prepared from adipose tissue and proliferate rapidly. The injected cells can secrete a number of growth factors to promote local angiogenesis in the ischemic area.

\section{Clinical Application in Autologous Cell Therapy}

Therapeutic angiogenesis, a strategy to treat tissue ischemia by promoting the proliferation of collateral vessels, has emerged as one of the most promising therapies developed to date ${ }^{13,14)}$. Therapeutic potential of various angiogenic molecules has been reported in animal models and humans with ischemic disease ${ }^{15,16)}$. Recently, autologous transplantation of bone marrow (BM) stromal cells or endothelial cell (EC) progenitors has been shown to enhance angiogenesis or peripheral blood flow, and these cells were incorporated into sites of angiogenesis after tissue ischemia of the limb, retina, and myocardium ${ }^{17)}$. However, it has also been suggested that bone marrow mononuclear cells possess various characteristics of stem cells for mesenchymal tissues ${ }^{18)}$ and secrete a broad spectrum of angiogenic or anti-angiogenic cytokines, such as interleukin- $1 \beta$, which would play a role in the process of angiogenesis ${ }^{19)}$.

We and others generated a mouse ischemic hindlimb model and evaluated the therapeutic effect of injected ADSC in comparison to bone marrow cells. The angiogenic score was improved in the ADSC-treated group, in which blood flow was evaluated by laser Doppler imaging and capillary density by immunostaining with anti-CD31 antibody, compared to that in the control group. There was no significant difference between injected ADSC and bone marrow cells. Moreover, in rodents, the presence of hematopoitic stem cells among ADSC has been suggested, and the presence of a cell population expressing the stem cell marker CD34 has been shown in ADSC from human adipose tissue ${ }^{20)}$. These cells could differentiate into endothelial cells and participate in the formation of vessels, and interestingly, administration of adipose tissue-derived cells could potentially affect revascularization to a degree similar to the administration of $\mathrm{BM}-\mathrm{MNC}^{12)}$. These results suggest that both hematopoietic and mesenchymal stem cells from adipose tissue can restore blood flow in the ischemic hindlimb on direct injection, but their mechanisms may be different. A proportion of hematopoietic stem cells can be induced to differentiate into vascular cells, leading to the involvement of neovessel formation, and the majority of injected mesenchymal stem cells can upregulate the expression of angiogenic cytokines by autocrine and paracrine actions in the ischemic area. We speculate that the injection of cells does not strictly mimic the natural course of infused cells, and stem cells cultured under special conditions can undergo changes in terms of their capacity to be incorporated into the target tissue (Fig. 2).

Recent reports demonstrated that these ADSC can be induced to differentiate into cardiac myocytes, similar to bone marrow cells ${ }^{21}$, which could be excellent for regenerative cell therapy for severe heart failure patients. However, the true in vivo differentiation capacity of adult BM stem cells and their possible con- 
tribution to non-hematopoietic cells and tissues including cardiac myocytes remain controversial. We need to carefully observe whether the surviving cells represent "differentiation" or "fusion", and how long these injected cells can function in the heart. We have to judge whether stem cell transplantation is "regenerative cell therapy" or "cell-based cytokine therapy".

\section{Advantage of ADSC Compared to MSC}

Despite their promising potential for regenerative applications, the fundamental scarcity of endothelial progenitor cell populations in the hematopoietic system constitutes an important limitation of primary endothelial progenitor cell transplantation. It was reported that ex vivo expansion of endothelial progenitor cells cultured from the peripheral blood of healthy human volunteers yielded about $5.0 \times 10^{6}$ cells per $100 \mathrm{ml}$ of blood, while heterologous transplantation requires $0.5 \sim 2.0 \times 10^{4}$ human endothelial progenitor cells per gram of body weight (of the recipient mouse) to achieve satisfactory reperfusion of the ischemic hindlimb ${ }^{22}$. In fact, the amount of autologous BM blood aspirated for therapeutic neovascularization was approximately $500 \mathrm{ml}$ per person (i.e., $0.1 \%$ of body weight ${ }^{1)}$. This suggests a practical limitation of endothelial progenitor cell transplantation; namely, the volume of blood required to extract an adequate number of endothelial progenitor cells for autologous transplantation. The main benefit of our ADSC is that they can be easily harvested from patients by a simple, minimally invasive method and also easily cultured ( 1 $\times 10^{5}$ cells from one mouse and $20 \mathrm{ml}$ of lipoaspiration from a human). Moreover, cultured populations of ADSC can be expanded more rapidly (more than 10 times within one week), and long-term cultured cells after some passages still retain their mesenchymal pluripotency, with expression of Sca1 and CD44. This suggests that ADSC could be a good candidate as a novel source of cell therapy in cardiovascular disease.

In the field of translational research, a preclinical project using ADSC has already started at MCTR (Medical Center for Translational Research) at Osaka University. The project involves not only therapeutic angiogenesis, but also other forms of regenerative medicine. We have developed an ADSC culture system from human white adipose tissue in the Cell Processing Center at MCTR, which can be regulated under the control of GMP. The protocol of our projects using ADSC has been approved by the evaluation committee of MCTR, and one of the projects is now in the early phase of clinical trials to evaluate safety and efficacy. We believe that ADSC will be a good op- tion for regenerative cell-based medicine in the near future.

\section{Acknowledgements}

This work was partially supported by grants from Takeda Foundation and by a Grant-in-aid from The Ministry of Education, Science, Sports and Culture of Japan.

\section{References}

1) Tateishi-Yuyama E, Matsubara $H$, Murohara T, Ikeda U, Shintani S, Masaki H, Amano K, Kishimoto Y, Yoshimoto K, Akashi H, Shimada K, Iwasaka T, and Imaizumi T: Therapeutic angiogenesis for patients with limb ischaemia by autologous transplantation of bone-marrow cells: a pilot study and a randomised controlled trial. Lancet, 2002; 360:427-435.

2) Orlic D, Kajstura J, Chimenti S, Jakoniuk I, Anderson SM, Li B, Pickel J, McKay R, Nadal-Ginard B, Bodine DM, Leri A, and Anversa P: Bone marrow cells regenerate infarcted myocardium. Nature, 2001; 410:701-705.

3) Erickson GR, Gimble JM, Franklin DM, Rice HE, Awad $\mathrm{H}$, and Guilak F: Chondrogenic potential of adipose tissue-derived stromal cells in vitro and in vivo. Biochem Biophys Res Commun, 2002; 18:763-769.

4) Safford KM, Hicok KC, Safford SD, Halvorsen YD, Wilkison WO, Gimble JM, and Rice HE: Neurogenic differentiation of murine and human adipose-derived stromal cells. Biochem Biophys Res Commun, 2002; 7:371379.

5) Halvorsen YD, Franklin D, Bond AL, Hitt DC, Auchter C, Boskey AL, Paschalis EP, Wilkison WO, and Gimble JM: Extracellular matrix mineralization and osteoblast gene expression by human adipose tissue-derived stromal cells. Tissue Eng, 2001; 7:729-741.

6) Zuk PA, Zhu M, Ashjian P, De Ugarte DA, Huang JI, Mizuno H, Alfonso ZC, Fraser JK, Benhaim P, and Hedrick $\mathrm{MH}$ : Human adipose tissue is a source of multipotent stem cells. Mol Biol Cell, 2002; 13:4279-4295.

7) Katz AJ, Tholpady A, Tholpady SS, Shang H, and Ogle RC: Cell surface and transcriptional characterization of human adipose-derived adherent stromal (hADAS) cells. Stem Cells, 2005; 23:412-423.

8) Nakagami H, Maeda K, Morishita R, Iguchi S, Nishikawa T, Takami Y, Kikuchi T, Saito Y, Tamai K, Ogihara T, and Kaneda Y: Novel autologous cell therapy in ischemic limb disease through growth factor secretion by cultured adipose tissue-derived stromal cells. Arterioscler Thromb Vasc Biol, 2005; 25:2542-2547.

9) Peister A, Mellad JA, Larson BL, Hall BM, Gibson LF, and Prockop DJ: Adult stem cells from bone marrow (MSCs) isolated from different strains of inbred mice vary in surface epitopes, rates of proliferation, and differentiation potential. Blood, 2004; 103:1626-1628.

10) Rehman J, Considine RV, Bovenkerk JE, Li J, Slavens CA, Jones RM, and March KL: Obesity is associated with 
increased levels of circulating hepatocyte growth factor. J Am Coll Cardiol, 2003; 41:1408-1413.

11) Rehman J, Traktuev D, Li J, Merfeld-Clauss S, TemmGrove CJ, Bovenkerk JE, Pell CL, Johnstone BH, Considine RV, and March KL: Secretion of angiogenic and antiapoptotic factors by human adipose stromal cells. Circulation, 2004; 109:1292-1298.

12) Planat-Benard V, Silvestre JS, Cousin B, Andre M, Nibbelink M, Tamarat R, Clergue M, Manneville C, SaillanBarreau C, Duriez M, Tedgui A, Levy B, Penicaud L, and Casteilla L: Plasticity of human adipose lineage cells toward endothelial cells: physiological and therapeutic perspectives. Circulation, 2004; 109:656-663.

13) Carmeliet P: Angiogenesis in health and disease. Nat Med, 2003; 9:653-660.

14) Freedman SB, and Isner JM: Therapeutic angiogenesis for ischemic cardiovascular disease. J Mol Cell Cardiol, 2001; 33:379-393.

15) Freedman SB, and Isner JM: Therapeutic angiogenesis for coronary artery disease. Ann Intern Med, 2002; 136:54-71.

16) Morishita R, Aoki M, Hashiya N, Makino H, Yamasaki K, Azuma J, Sawa Y, Matsuda H, Kaneda Y, and Ogihara T: Safety evaluation of clinical gene therapy using hepatocyte growth factor to treat peripheral arterial disease. Hypertension, 2004; 44:203-209.
17) Rafii S, and Lyden D: Therapeutic stem and progenitor cell transplantation for organ vascularization and regeneration. Nat Med, 2003; 9:702-712.

18) Prockop DJ: Marrow stromal cells as stem cells for nonhematopoietic tissues. Science, 1997; 276:71-74.

19) Maruyama K, Mori Y, Murasawa S, Masaki H, Takahashi N, Tsutusmi Y, Moriguchi Y, Shibazaki Y, Tanaka Y, Shibuya M, Inada M, Matsubara H, and Iwasaka T: Interleukin-1 beta upregulates cardiac expression of vascular endothelial growth factor and its receptor KDR/flk-1 via activation of protein tyrosine kinases. J Mol Cell Cardiol, 1999; 31:607-617.

20) Miranville A, Heeschen C, Sengenes C, Curat CA, Busse $\mathrm{R}$, and Bouloumie A: Improvement of postnatal neovascularization by human adipose tissue-derived stem cells. Circulation, 2004; 110:349-355.

21) Planat-Benard V, Menard C, Andre M, Puceat M, Perez A, Garcia-Verdugo JM, Penicaud L, and Casteilla L: Spontaneous cardiomyocyte differentiation from adipose tissue stroma cells. Circ Res, 2004; 94:223-229.

22) Kalka C, Masuda H, Takahashi T, Kalka-Moll WM, Silver M, Kearney M, Li T, Isner JM, and Asahara T: Transplantation of ex vivo expanded endothelial progenitor cells for therapeutic neovascularization. Proc Natl Acad Sci USA, 2000; 97:3422-3427. 